\title{
Effect of operating conditions on performance of silica gel-water air-fluidised desiccant cooler
}

\author{
Zbigniew Rogala $^{1^{*}}$, Piotr Kolasiński ${ }^{1}$, and Zbigniew Gnutek $^{1}$ \\ ${ }^{1}$ Department of Thermodynamics, Theory of Machines and Thermal Systems, Wrocław University of \\ Science and Technology, Wybrzeże Wyspiańskiego 27, 50 - 370 Wrocław, Poland
}

\begin{abstract}
Fluidised desiccant cooling is reported in the literature as an efficient way to provide cooling for air-conditioning purposes. The performance of this technology can be described by electric and thermal Coefficients of Performance (COP) and Specific Cooling Power (SCP). In this paper comprehensive theoretical study was carried out in order to assess the effect of operating conditions such as: superficial air velocity, desiccant particle diameter, bed switching time and desiccant filling height on the performance of fluidised desiccant cooler (FDC). It was concluded that FDC should be filled with as small as possible desiccant particles featuring diameters and should not be operated with shorter switching times than optimum. Moreover in order to efficiently run such systems superficial air velocities during adsorption and desorption should be similar. At last substantial effect of desiccant filling height on performance of FDC was presented.
\end{abstract}

\section{Introduction}

Fluidised desiccant cooling is reported as an efficient way to provide cooling for airconditioning purposes [1]. This technology allows to convert low-temperature heat [2] (even lower than $50{ }^{\circ} \mathrm{C}[3]$ ) into cooling effect. Scheme of simple fluidised desiccant cooler (FDC) is presented in the Fig. 1. The system consists of two fluidised beds filled with desiccant (in this case silica gel) which are periodically supplied with hot or cold air. The fan (4) blows the air through the air cooler (5). Then the air enters fluidised bed (3). Due to adsorption the air is dehumidified and warmed up. The dehumidified air is cooled again (2) and at last it is humidified (1) what results in air temperature drop. Process of direct evaporative cooling can be replaced by indirect process so-called Maisotsenko cycle [4] which may provide less humid air for better thermal comfort. Simultaneously in the second fluidised bed the desiccant undergoes regeneration. The fan (8) blows the air through recovery heat exchanger (7) and the air heater (6). Then the hot air enters the fluidised bed, where due to high air temperature, desorption of water from the desiccant takes place. At last outlet regeneration air flows again through recovery heat exchanger (7). For better understanding described processes are illustrated on psychrometric chart which is presented in Fig. 2. FDC requires electric power to run fans and thermal power to regenerate

\footnotetext{
* Corresponding author: zbigniew.rogala@pwr.edu.pl
} 
desiccant after adsorption. Therefore its performance can be described by thermal and electric COPs which are the ratios of cooling output to thermal or electric input. Another useful parameter describing the performance of FDC is Specific Cooling

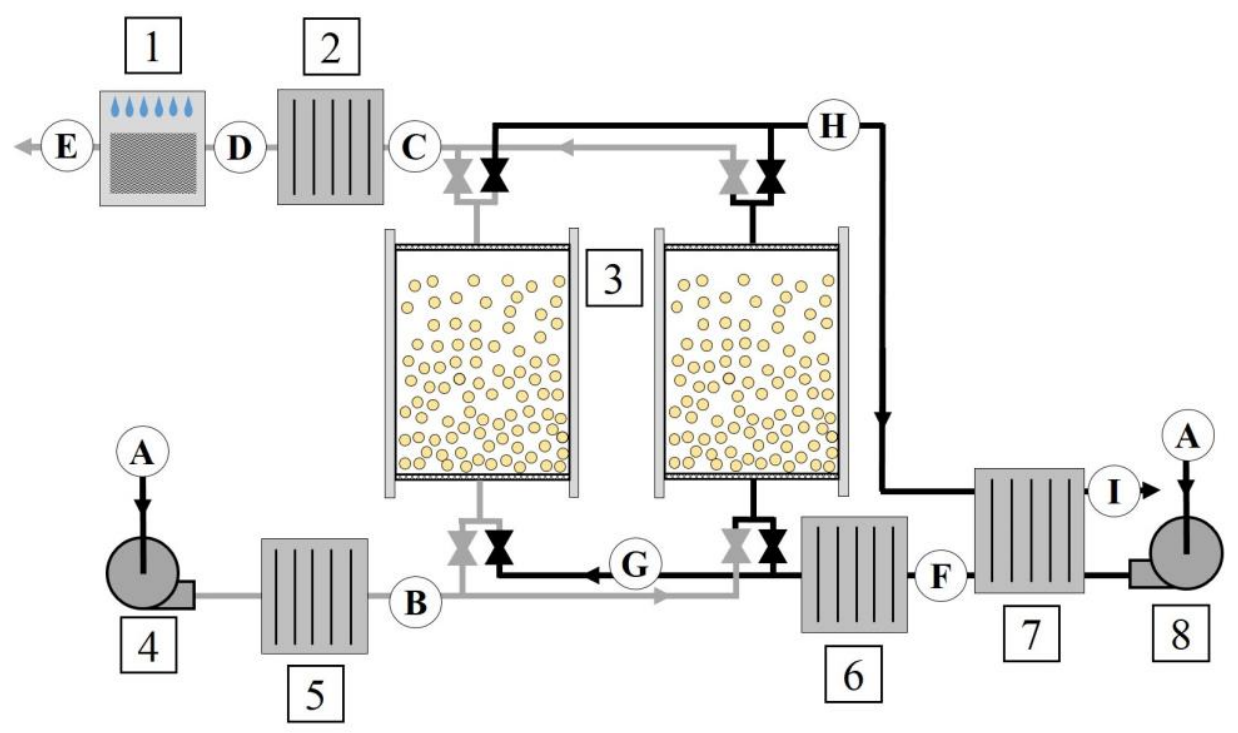

Fig. 1. Scheme of simple fluidised desiccant cooler (FDC). 1 - Humidifier, 2 - Air cooler, 3 Fluidised beds, 4 - Electric fan, 5 - Air cooler, 6 - Air heater, 7 - Heat recovery, 8 - Electric fan. Letters in circles correspond to processes presented in Fig.2.

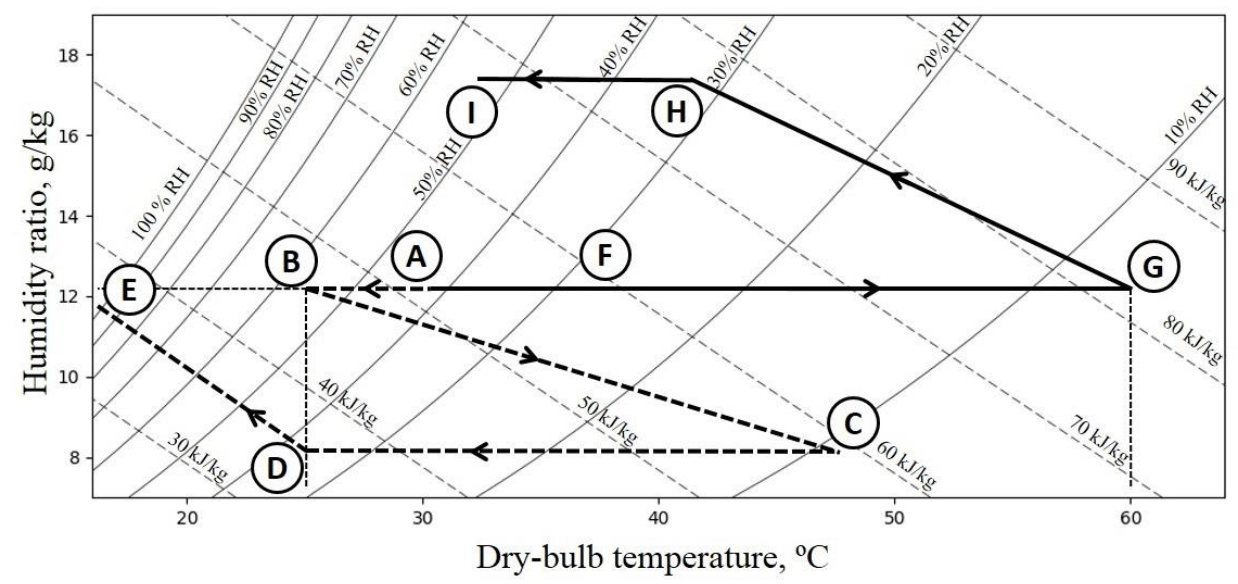

Fig. 2 Air processing in FDC. Letters in circles correspond to Fig. 1.

Power (SCP) which is cooling power obtained per unit mass of desiccant. Assuming that entire change of desiccant water uptake generates cooling effect and pressure drop on fluidised bed is described by [1]

$$
\Delta P=H_{d}(1-\varepsilon)\left(\rho_{p}-\rho_{g}\right) g
$$

thermal and electric COPs and SCP can be expressed as follows 


$$
\begin{gathered}
C O P_{e l}=\Delta w H_{e v} \eta_{f a n} /\left[\left(\mathrm{U}_{\mathrm{ads}}+\mathrm{U}_{\mathrm{des}}\right) \mathrm{g} t_{s w}\right] \\
C O P_{t h}=\rho_{d} \Delta w H_{e v} H_{d} /\left(\rho_{g} \Delta T_{\text {mean }} U_{d e s} c_{g} t_{s w}\right) \\
S C P=\Delta w H_{e v} / t_{s w}
\end{gathered}
$$

Where $\varepsilon$ is void fraction of the fluidised bed, $g$ is gravitational acceleration, $\Delta w$ is change of desiccant water uptake, $H_{e v}$ is heat of evaporation, $\Delta T_{\text {mean }}$ is mean air temperature difference between outlet and inlet during desorption and $c_{g}$ is specific heat of air. The performance of FDC mainly depends on adsorption/desorption processes taking place in fluidised beds. On the other hand these processes depend on operating conditions such as bed switching time $t_{s w}$, desiccant particles diameter $d_{p}$, superficial velocity $U_{d e s}$ and $U_{a d s}$ and mass of desiccant $M_{d}$ in the fluidised bed. Influence of these parameters on FDC COPs and SCP were not yet investigated. Few prototypes of FDC were already presented in the literature $[3,5]$ and their electric COP and SCP did not exceed 0.37 and $285 \mathrm{~W} / \mathrm{kg}$, respectively. It was probably caused by improper selection of operating conditions. Analysis of the effect of abovementioned operating conditions will provide recommendations and guides on efficient FDC operating. Moreover, it contributes to better understanding of FDC operation and its limitations.

\section{Results and discussion}

The theoretical analysis of adsorption was carried out basing on modelling method presented in [1] while desorption was calculated basing on [6-8]. Basing on abovementioned references computational code was implemented in Python and run explicitly. The modelling was performed for regeneration temperature of $60{ }^{\circ} \mathrm{C}$, cooling temperature of $25{ }^{\circ} \mathrm{C}$ and humidity ratio of $12 \mathrm{~g} / \mathrm{kg}$. Parameters which were kept constant during the modelling are presented in Table 1.

Table 1.Constant parameters used in modelling

\begin{tabular}{|c|c|c|c|c|c|}
\hline Parameter & $\begin{array}{c}\text { Symbol } \\
\text { and unit }\end{array}$ & Value & Parameter & $\begin{array}{c}\text { Symbol } \\
\text { and unit }\end{array}$ & Value \\
\hline Air density & $\rho_{\mathrm{g}}, \mathrm{kgm}^{-3}$ & 1.2 & $\begin{array}{c}\text { Fluidised } \\
\text { bed diameter }\end{array}$ & $\mathrm{D}, \mathrm{m}$ & 0.28 \\
\hline $\begin{array}{c}\text { Desiccant } \\
\text { density }\end{array}$ & $\rho_{\mathrm{d}}, \mathrm{kgm}^{-3}$ & 800 & $\begin{array}{c}\text { Fan } \\
\text { efficiency }\end{array}$ & $\eta_{\text {fan }},-$ & 0.8 \\
\hline
\end{tabular}

Moreover some of the parameters were varied during modelling (see Table 2).

Table 2 Parameters which were varied during the modelling

\begin{tabular}{|c|c|c|c|c|c|c|}
\hline Operating condition & & $\mathrm{d}_{\mathrm{d}}, \mathrm{mm}$ & $\mathrm{t}_{\mathrm{sw}}, \mathrm{s}$ & $\begin{array}{c}\mathrm{U}_{\mathrm{ads}}, \\
\mathrm{ms}^{-1}\end{array}$ & $\begin{array}{c}\mathrm{U}_{\mathrm{des}}, \\
\mathrm{ms}^{-1}\end{array}$ & $\mathrm{H}_{\mathrm{d}}, \mathrm{m}$ \\
\hline Desiccant particle diameter Fig. 2 & $\mathrm{d}_{\mathrm{d}}$ & $1-5$ & optimum & 2 & 2 & 0.05 \\
\hline Switching time Fig 3. & $\mathrm{t}_{\mathrm{sw}}$ & $1,3,5$ & $200-1500$ & 2 & 2 & 0.04 \\
\hline $\begin{array}{c}\text { Superficial air velocities during } \\
\text { adsorption and desorption Fig 4. }\end{array}$ & $\begin{array}{c}\mathrm{U}_{\mathrm{ads}}, \\
\mathrm{U}_{\mathrm{des}}\end{array}$ & 1 & optimum & $1-6$ & $1-6$ & 0.04 \\
\hline $\begin{array}{c}\text { Superficial air velocity during adsorption } \\
\text { and desiccant filling height Fig.5 }\end{array}$ & $\begin{array}{c}\mathrm{U}_{\mathrm{ads}}, \\
\mathrm{H}_{\mathrm{d}}\end{array}$ & 1 & optimum & $2-6$ & 2 & $0.01-0.1$ \\
\hline
\end{tabular}


Firstly, the effect of desiccant particle diameter on performance of FDC was investigated. In FDC desiccant is simply poured into fluidised bed. During fluidisation each single particle has a direct contact with the air and therefore some of the limitations [9, 10] of other adsorption technologies are not present. On the other hand, desiccant particle diameter affect minimum fluidisation velocity [1] and termination velocity [11]. In order to maintain the proper FDC operation the fluidisation velocity must be kept between these velocities, otherwise either fluidisation will not occur (too low superficial air velocity) or desiccant may clog the upper sieve of fluidised bed and increase the pressure drop (too high superficial air velocity). Modelling was carried out for particles diameters ranging from 1 to $5 \mathrm{~mm}$ and its results are presented in Fig. 2. The parameters of modelling were set accordingly to Table 1 . Superficial velocities during adsorption and desorption were set to 2 $\mathrm{ms}^{-1}$ and desiccant filling height $H_{d}$ in each bed was set to $0.05 \mathrm{~m}$. Switching time is initially unknown and therefore range of switching times is analyzed at first and then the best result is selected. Optimum switching time is also presented in Fig. 2. Thermal COP (see Fig. 2a) is nearly constant, regardless of desiccant particle diameter and equals to ca. 0.5. On the other hand optimum electric COP and SCP strongly depend on desiccant particle diameter (see Figs $2 \mathrm{~b}$ and 2c). For desiccant particle of $5 \mathrm{~mm}$ electric COP and
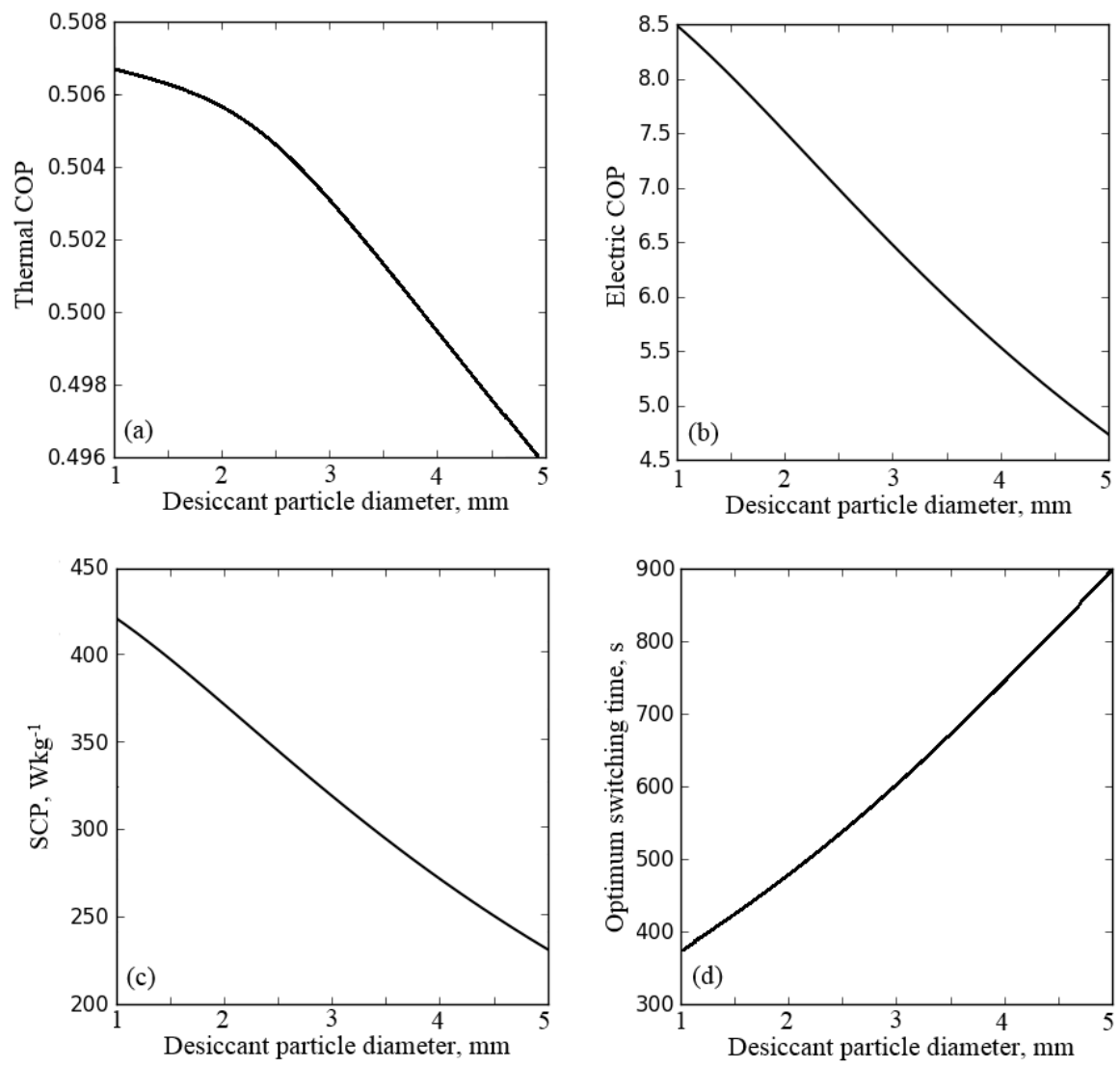

Fig. 1. Performance of fluidised desiccant cooler with respect to desiccant particle operated at optimum switching time: (a) Thermal COP, (b) Electric COP, (c) SCP, (d) Optimum switching time. 
SCP are equal to 4.7 and $240 \mathrm{~W} / \mathrm{kg}$ while for desiccant particle of $1 \mathrm{~mm}$ they are equal to 8.5 and $420 \mathrm{~W} / \mathrm{kg}$, respectively. The increase of electric COP and SCP for smaller desiccant particle diameters is caused, among other factors, by decrease of optimum switching time (Fig. 2d) which drops from $900 \mathrm{~s}$ for $5 \mathrm{~mm}$ particle to less than $400 \mathrm{~s}$ for $1 \mathrm{~mm}$ particle. Analysis of the effect of desiccant particle diameter on performance of FDC leads to conclusion that the performance increases with decreasing particles diameter. On the other hand, as was already mentioned, desiccant particle diameter affect the minimum fluidisation and termination velocity of particles. Limitations related to this phenomena should be investigated in practice. Another important factor affecting performance of FDC is switching time. It is already known that for certain switching time SCP and electric COP achieve the highest possible values. Nevertheless the effect of switching time on FDC performance is still unknown. Therefore the analysis in this matter was carried out and its results are presented in Fig. 3. The modelling was carried out for superficial air velocities equal to $2 \mathrm{~ms}^{-1}$ (during adsorption and desorption) and desiccant filling height of $0.04 \mathrm{~m}$. Desiccant particles featuring diameters of 1, 3 and $5 \mathrm{~mm}$ were analyzed. Thermal COP (see Fig. 3a) increases with the increase of switching time for each analyzed desiccant particle
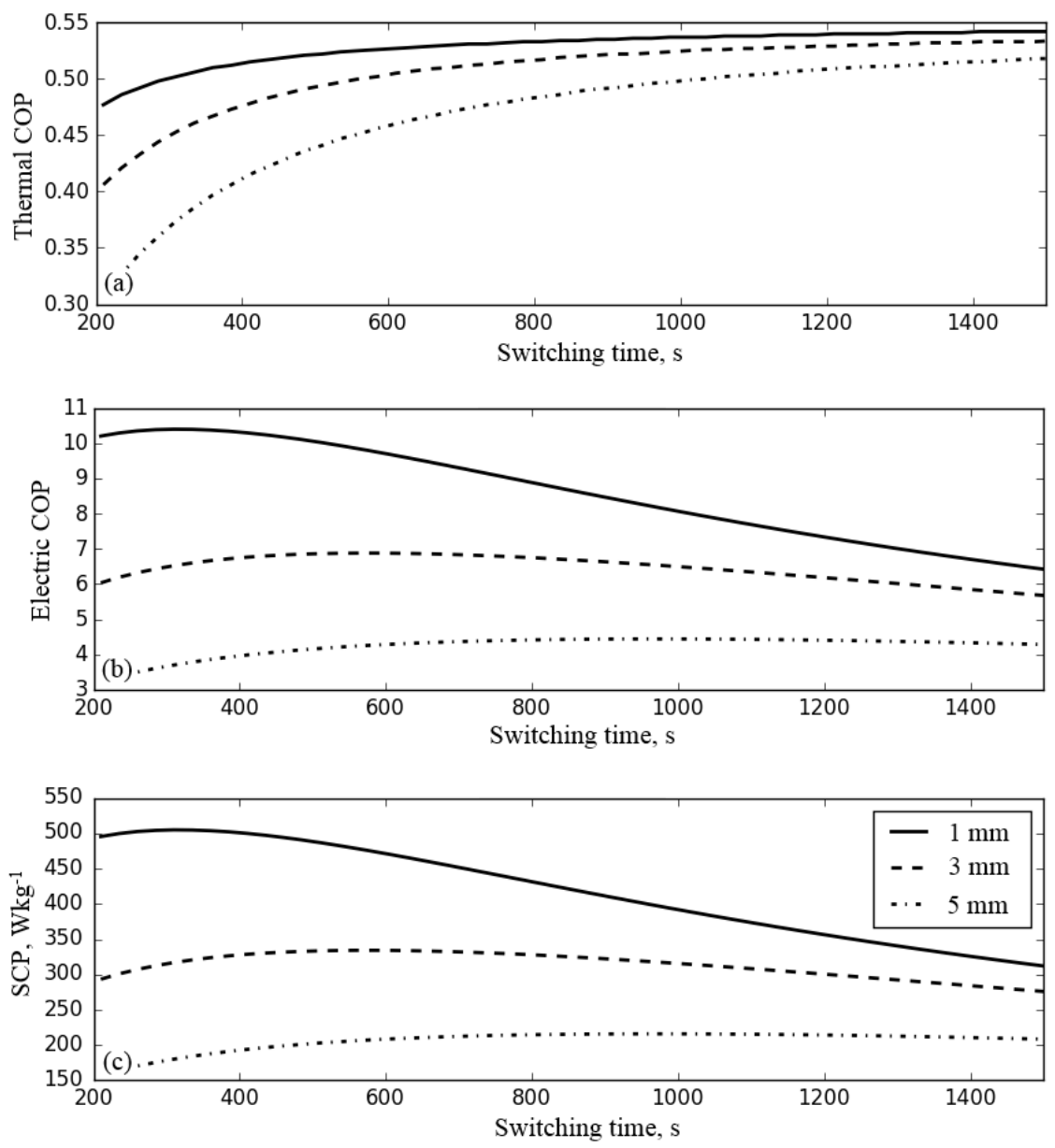

Fig. 2. Performance of fluidised desiccant cooler with respect to switching time for desiccant particle diameters $1 \mathrm{~mm}, 3 \mathrm{~mm}$ and $5 \mathrm{~mm}$ : (a) Thermal COP, (b) Electric COP, (c) SCP. 
diameter. Moreover, thermal COP is greater for smaller desiccant particles. For desiccant particle diameter of $1 \mathrm{~mm}$ thermal COP remains high in the investigated range of switching times and its maximum value reaches ca. 0.54. Electric COP (see Fig. 3b) and SCP (see Fig. 3c) for certain switching time reach their maximum value. The larger desiccant particle is the lower maximum electric COP and SCP are and the longer optimum switching time is. Such characteristics results from kinetics of adsorption. Initially adsorption is rapid but it decreases with time as desiccant water uptake increases towards equilibrium. In case of operating on switching times shorter than optimum performance of FDC is generally deteriorated and such operating conditions are undesirable. On the other hand operating on switching time longer than optimum causes the increase of thermal COP but at the cost of electric COP and SCP. In short, switching time should be not shorter than optimum switching time which for desiccant particle of $1 \mathrm{~mm}$ in considered case is about $350 \mathrm{~s}$.
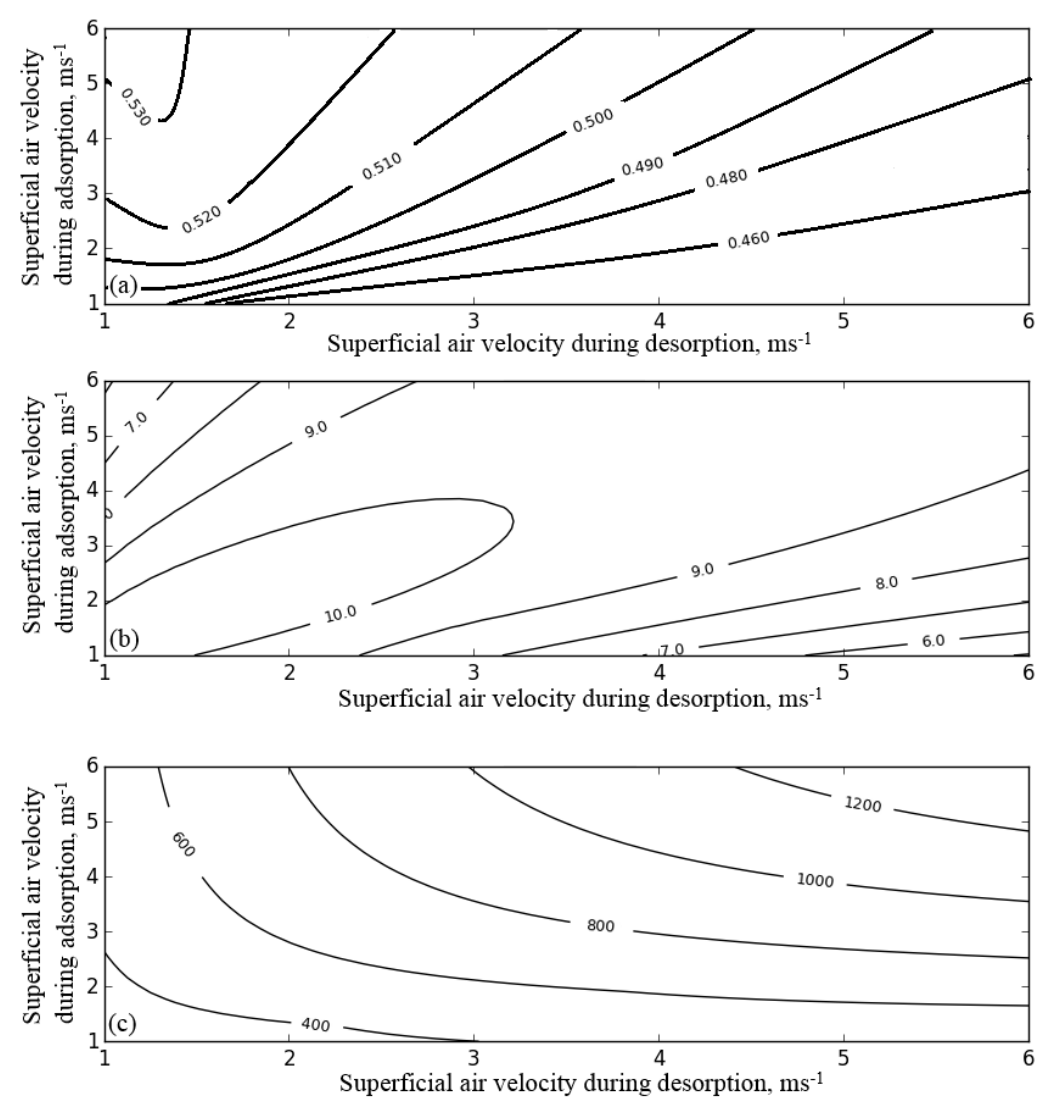

Fig. 3. Performance of fluidised desiccant cooler with respect to superficial air velocities during adsorption and desorption, operated at optimum switching time: (a) Thermal COP, (b) Electric COP, (c) SCP.

Longer switching times result in increased thermal COP while electric COP and SCP are decreased. FDC can be operated with range of superficial air velocities. Lower limit is minimum fluidisation velocity and upper limit is termination velocity. Superficial air velocity affects electric demand of fans and kinetics of adsorption. Moreover kinetics during adsorption and desorption is different. Therefore superficial air velocity may differ during these processes. Analysis of the effect of superficial air velocity was carried out for 
superficial air velocities ranging from 1 to $6 \mathrm{~ms}^{-1}$ and its results are presented in Fig. 4. The modelling was performed for desiccant particle diameter of $1 \mathrm{~mm}$ and desiccant filling height of $0.04 \mathrm{~m}$. Switching time was set to optimum in each case. Thermal COP of FDC (see Fig. 4a) is highest for high superficial air velocity during adsorption and low during desorption. When both superficial air velocities are the same, thermal COP remains nearly constant irrespective of superficial air velocities. Electric COP of FDC (see Fig. 4b) achieves the highest values for both superficial air velocities of ca. $2 \mathrm{~ms}^{-1}$. Electric COP also remains high when superficial air velocities during adsorption and desorption are similar. At last SCP (see Fig. 4c) is the highest when both superficial velocities are ca. 6 $\mathrm{ms}^{-1}$. In order to keep electric COP high FDC should be operated with similar superficial air velocities during adsorption and desorption. These velocities should be low in order to
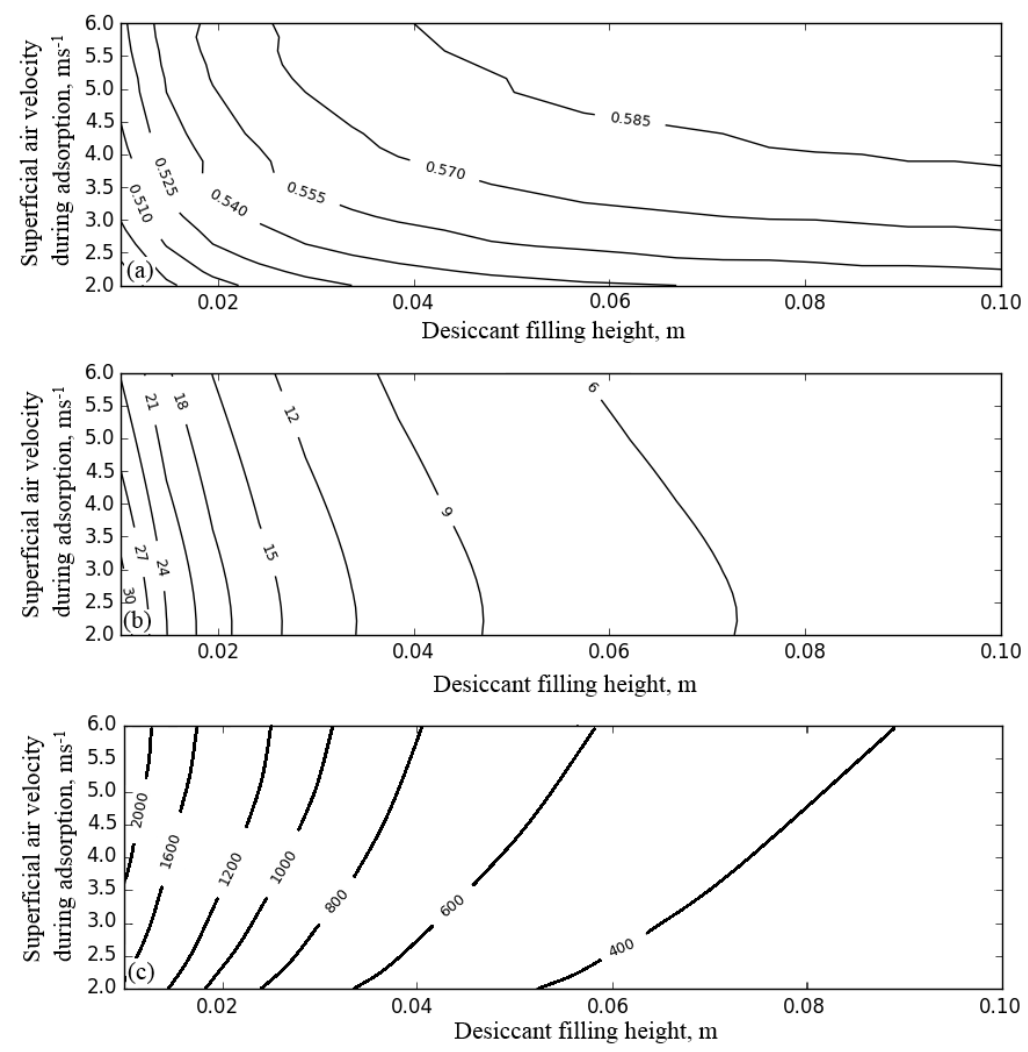

Fig. 4. Performance of FDC with respect to superficial air velocity during adsorption and desiccant filling height, operated at optimum switching time: (a) Thermal COP, (b) Electric COP, (c) SCP.

obtain higher thermal COP or high in order to obtain high SCP. At last, the effect of desiccant filling height on FDC performance was investigated. Desiccant filling height represents the mass of desiccant poured into the fluidised bed. This portion of desiccant will be either cooled or heated by the air stream flowing through the fluidised bed. Due to the limitations of superficial air velocity the amount of heating or cooling provided by the air stream is also limited. Therefore, the effect of desiccant filling height is analyzed along with superficial air velocity during adsorption. The modelling was carried out for desiccant particle diameter of $1 \mathrm{~mm}$ and superficial air velocity during desorption of $2 \mathrm{~ms}^{-1}$. 
Switching time was set to optimum. The modelling results are presented in Fig. 5. As it can be observed, the electric COP and SCP depend strongly on desiccant filling height. For higher fillings dependence on superficial air velocity becomes substantial too. Electric COP is generally higher than 9 for desiccant filling height lower than $0.04 \mathrm{~m}$. On the other hand, SCP decreases with the increase of filling height and superficial air velocity during adsorption. Desiccant filling height has opposite influence on thermal and electric COP. Thermal COP increases for higher fillings while electric COP drops. In the authors opinion it is of great importance to keep electric COP high which limits the increase of desiccant filling height.

\section{Conclusions}

The effect on performance of FDC of desiccant particle diameter, switching time, superficial air velocity and desiccant filling height was modelled and analyzed. Thermal and electric COP and SCP were investigated. The modelling results provided useful information on FDC efficient operating. Conclusions and recommendations are as follows:

- Desiccant particle diameter should be as small as it is possible. Technical aspects related to minimum fluidisation and termination velocities should be taken into account to avoid clogging.

- Switching time should not be shorter than optimum. Optimum switching time allows to obtain maximum electric COP and SCP. Switching time longer than optimum allows to increase thermal COP at the cost of SCP and electric COP. Optimum of bed switching time is not constant and depends on operating conditions. The effect of the individual parameters should be further investigated.

- In order to keep high electric COP FDC should be run with similar superficial air velocities during adsorption and desorption. In order to obtain higher thermal COP superficial velocities should be lower, on the other hand to obtain higher SCP the superficial air velocities should be higher.

- Desiccant filling height has opposite influence on electric and thermal COP. Increase of filling height leads to increase of thermal COP and SCP but on the other hand it leads to deterioration of electric COP.

1. C-H. Chen, G. Schmid, C-T. Chan, Y-C. Chiang, S-L. Chen, Appl. Therm. Eng. 89, 229 (2015)

2. A.M. Hamed, W.R.A. Rahman, S.H. El-Emam, Energ. 35, 2468 (2010)

3. C-H. Chen,S-S. Ma, P-H. Wu, Y-C. Chiang, S-L. Chen, Appl. Energ. 155, 708 (2015)

4. D. Pandelidis, S. Anisimov, W.M. Worek, P. Drąg, Energ. Buildings 140, 154 (2017)

5. Y-C, Chiang, C-H. Chen, Y-C. Chiang, S-L. Chen, Appl. Energ. 175, 199 (2016)

6. Y.C. Lee, L.C. Weng, P.C. Tseng, C.C. Wang, Heat Mass Transf. 51, 441(2014)

7. C.C. Ni, J. Y. San, Int. J. Heat Mass Tran. 45, 1839 (2002)

8. A.A. Pesaran, A.F. Mills, Int. J. Heat Mass Tran. (1986)

9. S. Salvatore, A. Sapienza, A. Frazzica, A. Freni, I.S. Girnik, Appl. Energ. 134, 11 (2014)

10. V. Brancato, L. Gordeeva, A.Sapienza, A. Freni, A. Frazzica, Appl. Therm. Eng. 105, 28 (2016)

11. Y. Wen-Ching, Handbook of fluidization and fluid-particle systems (Marcel Dekker, New York, 2003) 